Z. klin. Chem. u. klin. Biochem.

9. Jg., S. 107-110, März 1971

\title{
Flammenphotometrische Lithium-Bestimmung im Serum
}

\author{
Von R.'KLaus \\ Aus dem Analytischen Zentrallaboratorium der Firma E. Merck, Darmstadt \\ (Leiter: Abt.-Dir. Dr.J. Fries)
}

(Eingegangen am 2. September 1970)

\begin{abstract}
Es wird ein emissionsflammenphotometrisches Verfahren zur Bestimmung des Elementes Lithium in Human-Seren beschrieben. Da sich die Leistungsfähigkeit kommerzieller Meßanordnungen zur Erfassung der Lithium-Gehalte nicht-pathologischer Seren als nicht ausreichend erwies, wird von der emissionssteigernden Wirkung organischer Lösungsmittel Gebrauch gemacht. Die Analyse einer begrenzten Anzahl Seren läßt einen physiologischen Lithium-Mittelwert von $<3 \mu \mathrm{g} / 100 \mathrm{~m} /$ bei einer Nachweisgrenze des Verfahrens von $0,5 \mu \mathrm{g} / 100 \mathrm{ml}$ erwarten.
\end{abstract}

\section{Determination of serum litbium by flame photometry}

An emission flame photometric method for the determination of the element lithium in human sera is described. As the performance of commercial measuring devices proved to be inadequate for lithium concentrations of non-pathological sera, the increase of emission by the presence of organic solvents is utilised. Analysis of a limited number of sera showed a physiological lithium mean of $<3 \mu \mathrm{g} / 100 \mathrm{~m} /$ with a detection limit of $0.5 \mu \mathrm{g} / 100 \mathrm{~m} /$.

Wenn auch über die Bedeutung des Elementes Lithium in der Humanbiologie noch keine endgültige Prognose gestellt werden kann, so dürfte dieses doch beim menschlichen Stoffwechsel bzw. bei einigen Erkrankungsformen und deren Therapie von einem gewissen Interesse sein. Einige zusammenfassende Hinweise werden von Lang und Herrmann (1) angegeben. Doerr und STAMM (2) erwähnen das Element Lithium in $\mathrm{Zu}-$ sammenhang mit der Therapie verschiedener psychiatrischer Erkrankungen. Nach Angaben dieser Autoren liegen die Serumlithiumwerte von unter Therapie stehenden Patienten um 2-3 Zehnerpotenzen oberhalb des physiologischen Mittelwertes.

Dieser beträgt nach älteren Literaturangaben (3) $30 \mathrm{ng}$ $\mathrm{Li} / \mathrm{ml}$ Serum. Der von Lang und Herrmann aus 50 Seren ermittelte Lithium-Schwankungsbereich erstreckt sich bis etwa $50 \mathrm{ng} \mathrm{Li} / \mathrm{ml}$ Serum. Wenn auch zur Festlegung eines physiologischen Mittelwertes die Heranziehung von 50 Einzelwerten als nicht ausreichend betrachtet werden kann, so läßt eine Interpretation der Untersuchungen von LANG und HerRMANN einen solchen von $<15 \mathrm{ng} / \mathrm{m} /$ Serum erwarten.

Während für die emissionsflammenphotometrische $\mathrm{Li}$ thium-Analyse in der Größenordnung $\mathrm{mg} / 100 \mathrm{~m} / \mathrm{mit}$ handelsüblichen Geräten prinzipiell keine Schwierigkeiten bestehen (2), sind Analysen im Bereich des wahrscheinlichen physiologischen Mittelwertes nur mit einem etwas größeren analytischen Aufwand durchführbar.

Dies ist einerseits durch die Tatsache bedingt, daß der $\mathrm{zu}$ erwartende physiologische Lithium-Mittelwert in der Größenordnung der mit handelsüblichen Photometern erreichbaren Nachweisgrenze liegt, andererseits dadurch, daß das Emissionsspektrum in der Umgebung der Lithium-Linie $6708 \AA$ einen stark wellenlängenabhängigen Verlauf zeigt, der darüber hinaus in seiner
Größe nicht unabhängig von der Zusammensetzung der Seren ist. Diesem Umstand kann bei der Analyse zunächst dadurch Rechnung getragen werden, daß man

1. eine relativ geringe Nachverdünnung der Seren vornimmt,

2. nach dem sogenannten Zumischungsverfahren arbeitet,

3. die Untergrundbestimmung aus den registrierten Spektren durchführt.

Demgegenüber steht die Arbeitstechnik, wie sie in vielen klinisch-diagnostischen Laboratorien zur Bestimmung der Elemente Natrium, Kalium, Calcium und Magnesium in biologischem Material angewendet wird (4):

Setzt man lineare Eichkurven für die einzelnen Elemente voraus, so kann nach Messung der stark verdünnten Seren bzw. entsprechender Eich- und Blindlösungen bei jeweils einer vorgegebenen Wellenlänge über eine Proportion die unbekannte Metallkonzentration ermittelt werden. Mit den folgenden Ausführungen soll nun der Versuch unternommen werden, die Anwendbarkeit dieser Arbeitsweise unter Beachtung der erwähnten kritischen Punkte zu prüfen.

\section{Beschreibung der Meßanordnung}

Erfabrungsgemäß bereitet der Einsatz nicht handelsüblicher Meßanordnungen in klinischen Laboratorien gewisse Schwierigkeiten. Die Festlegung der Mcßbedingungen wurde daher von dem Gedanken bestimmt, dic Analyse sowohl ohne wesentliche apparative Veränderungen mit kommerziellen Flammenphotometern vornehmen zu können als auch charakteristische Meßparameter wie z. B. zu verwendende Gase bereits vorhandenen Analysenvorschriften für andere Elemente anzupassen.

Die Meßanordnung besteht aus cinem Spektralphotometer PMQ II mit Glasmonochromator und Flammenzusatz FA 1 der Fa. Carl Zeiss, Oberkochen. Als Strahlungsempfänger eignet sich ein Sekundärelektronenverviclfacher 1 P28 mit erhöhter Rotempfindlich- 
keit. Der Anschluß eines Schreibers sowie einer Wellenlängenautomatik zur Registrierung des photometrischen Signals ist lediglich für die notwendig gewesenen Vorversuche erforderlich. Zur Anregung eignet sich eine Sauerstoff-Acetylen-Flamme mit den Drukken für Sauerstoff etva $0,25 \mathrm{~kg} / \mathrm{cm}^{2}$ und Acetylen etwa $90 \mathrm{~mm}$ WS

\section{Beschreibung des Verfahrens}

In der Annahme, daß die Emissionsspektren der Seren im Bereich der Lithium-Linie $6708 \AA$ sowohl bezüglich der Strahlungsintensität der Linie als auch hinsichtlich des Untergrundes vorwiegend durch die Anwesenheit des Elementes Natrium bestimmt werden, sollten Analysen mit Proben, deren Natrium-Gehalte an den Grenzen des physiologischen Schwankungsbereiches der Seren liegen, wertvolle Aussagen über die Größe der zu erwartenden Beeinflussung ergeben. Als Probenmaterial eignen sich für diesen Versuch hinsichtlich der Alkalien bzw. Erdalkalien als Modellseren zu betrachtende Lösungen.

Abbildung 1 zeigt die Emissionsspektren für die in der Legende beschriebenen Lösungen. Die gewählte Lithium-Konzentration von $3 \mu \mathrm{g} / 100 \mathrm{~m} l$ geht auf Angaben

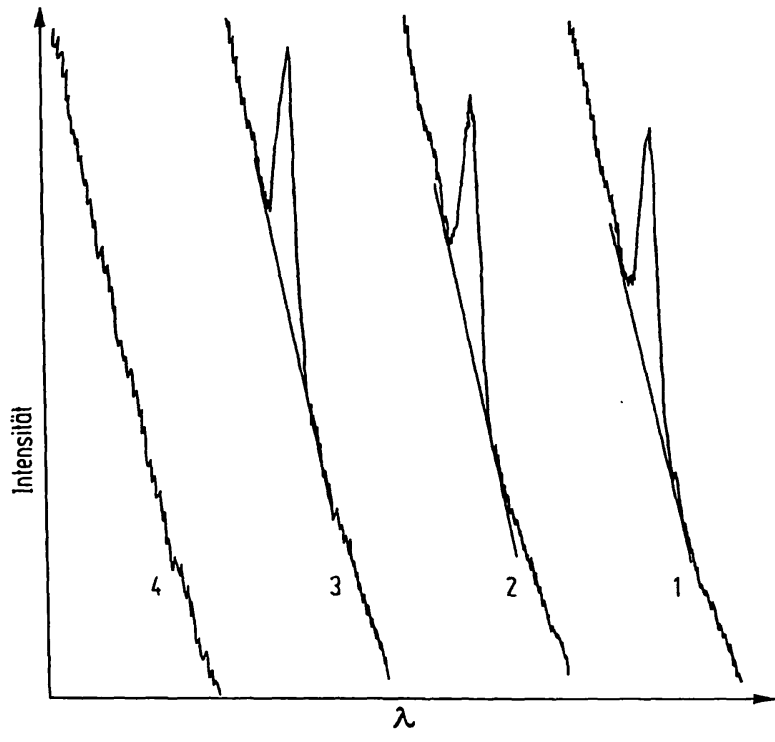

Abb. 1

Emissionsspektren serumähnlicher Lösungen im Bereich $6620 \AA<\lambda$ $<6800 \AA$, registriert mit einer effektiven Bandbreite des Monochromators von etwa $1,8 \mathrm{~nm}$.

Zusammensetzung der Lösungen in $\mathrm{g} / 100 \mathrm{ml}$ für Spektren $1-4$ : Konstante Bestandteile $\quad \mathrm{K}: 0,015 ; \quad \mathrm{Ca}: 0,010 ; \quad \mathrm{Mg}: 0,002$ Variable Bestandteile Spektrum Natrium

$\begin{array}{cccc}\text { Spektrum } & \text { Natrium } & \text { Lithium } \\ 1 & 0,300 & 3 \cdot 10^{-6} \\ 2 & 0,330 & 3 \cdot 10^{-0} \\ 3 & 0,360 & 3 \cdot 10^{-0} \\ 4 & 0,300 & 0\end{array}$

Die Meßlösungen sind mit Wasser $1: 4$ nachverdünnt

von Hinsberg und LANG (3) zurück. Der NatriumGehalt der Lösungen beträgt entsprechend des physiologischen Schwankungsbereiches $0,300 \mathrm{~g}, 0,330 \mathrm{~g}$, und $0,360 \mathrm{~g} / 100 \mathrm{ml}$.

Es sei vermerkt, daß im folgenden die Lösung mit dem Natrium-Gehalt $0,330 \mathrm{~g} / 100 \mathrm{ml}$ als Haupteichlösung, die entsprechende Lösung ohne Lithium als Blindlösung für Lithium bezeichnet wird. Aus den Spektren der mit Wasser 4:1 verdünnten Ausgangslösungen können nun einige wesentliche Schlüsse gezogen werden:
1. Der Untergrundverlauf in dem interessierenden Spektralbereich ist.äußerst kritisch.

2. Der Untergrund variiert geringfügig mit der Natrium-Konzentration und weiterhin

3. Eine Beeinflussung der Lithium-Emission durch wechselnde Mengen Natrium ist nicht erkennbar.

Sehr ausführliche Untersuchungen von LANG und HERRMANN (1) führen u. a. in den Punkten 2. und 3. zu dem gleichen Ergebnis. Darüber hinaus sind nach (1) Störungen der Lithium-Emission in Seren durch andere, in der Haupteichlösung nicht zusammengefaßte Elemente nicht zu erwarten. Eigene Versuche zur Veränderung der Steilheit des Untergrundverlaufes z. B. durch Verwendung einer Wasserstoff/Sauerstoff-Flamme brachten nicht das gewünschte Ergebnis. Von der Möglichkeit einer Verringerung der Untergrundsteilheit durch Wahl kleinerer effektiver Bandbreiten des Monochromators wurde kein Gebrauch gemacht, da diese eine Empfindlichkeitseinbuße zur Folge hat.

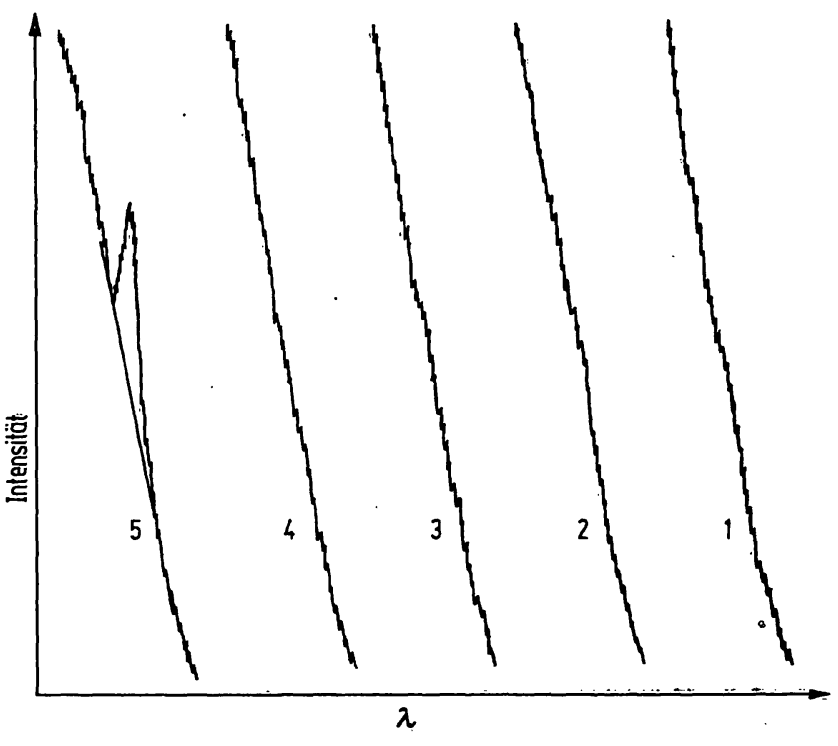

Abb. 2

Emissionsspektren von 4 Humanseren im Bereich $6640 \AA<\lambda$ $<6780 \AA$ (effektive Bandbreite des Monochromators etwa $1,8 \mathrm{~nm}$ ). Nachverdünnung mit Wasser 1:4. Spektrum 5: Lithium-Zusatz $3 \mu \mathrm{g} / 100 \mathrm{ml}$ Serum

Eine unter den gleichen Bedingungen durchgeführte Registrierung von 4 im Verhältnis 1:4 mit Wasser verdünnten Humanseren ist in Abbildung 2 wiedergegeben. Die Spektren 4 und 5 resultieren aus dem gleichen Serum, bei 5 wurde lediglich vor der Verdünnung ein Lithium-Zusatz von $3 \mu \mathrm{g} / 100 \mathrm{ml}$ hinzugefügt. Aus dem Verlauf dieser Speǩtren ist unter Berücksichtigung des Spektrums 4 (Abb. 1) zu entnehmen, daß der Lithium-Gehalt der 4 Seren unter der Nachweisgrenze dieser Analysentechnik liegt. Als obere Lithium-Schranke kann unter Heranziehung von Spektrum 5 ein Wert von $3 \mu \mathrm{g} / 100 \mathrm{~m} l$ angegeben werden. Bezüglich der Richtigkeit des; Zumischverfahrens bei der Lithium-Analyse in Seren sei an dieser Stelle auf die Untersuchungen von LANG und HERRMANN zurückgegriffen (1). 


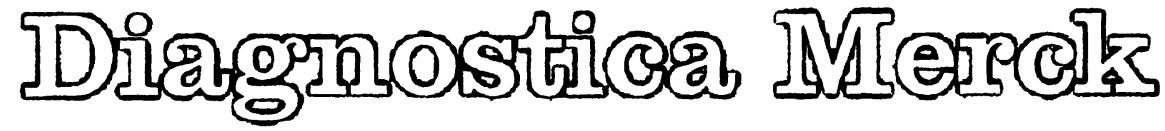

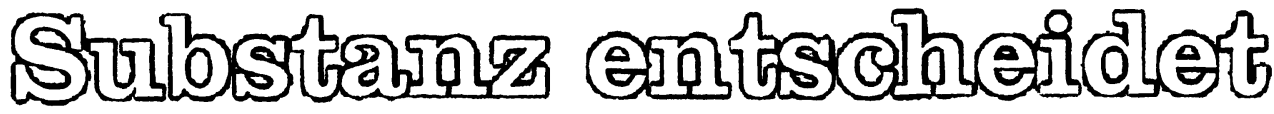
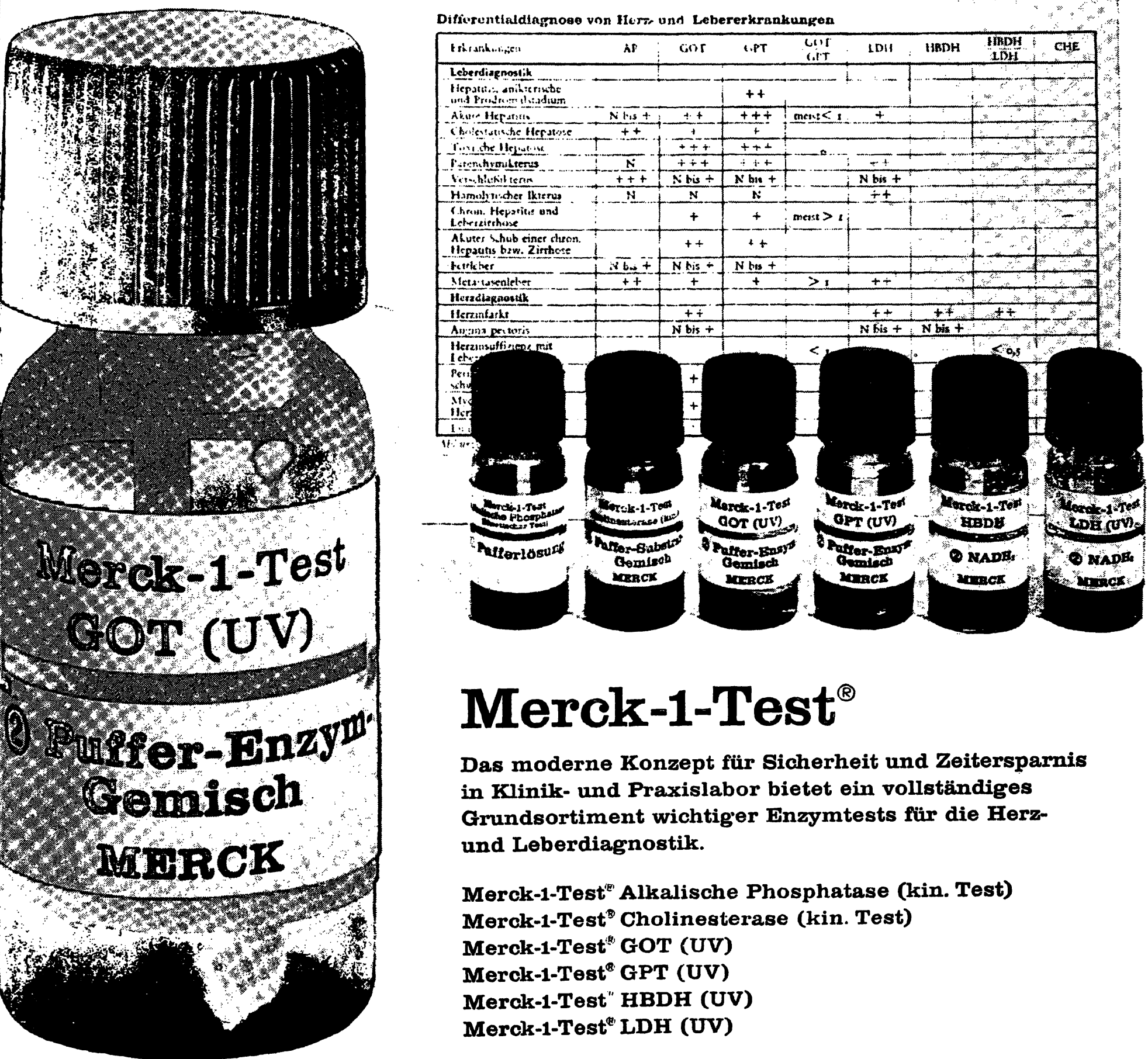

\section{Merck-1-Test ${ }^{\oplus}$}

Das moderne Konzept für Sicherheit und Zeitersparnis in Klinilk- und Praxislabor bietet ein vollständiges Grundsortiment wichtiger Enzymtests für die Herzund Leberdiagnostik.

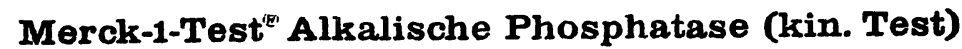
Merck-1-Test ${ }^{\text {B }}$ Cholinesterase (kin. Test)

Merck-1-Test ${ }^{\text {to }}$ GOT (UV)

Merck-1-Test ${ }^{\text {a }}$ GPT (UV)

Merck-1-Test" HBDH (UV)

Merck-1-Test LDH (UV)

Verlangen Sie bitte unseren Spezial-Prospekt.

E. Merck, Darmstadt 


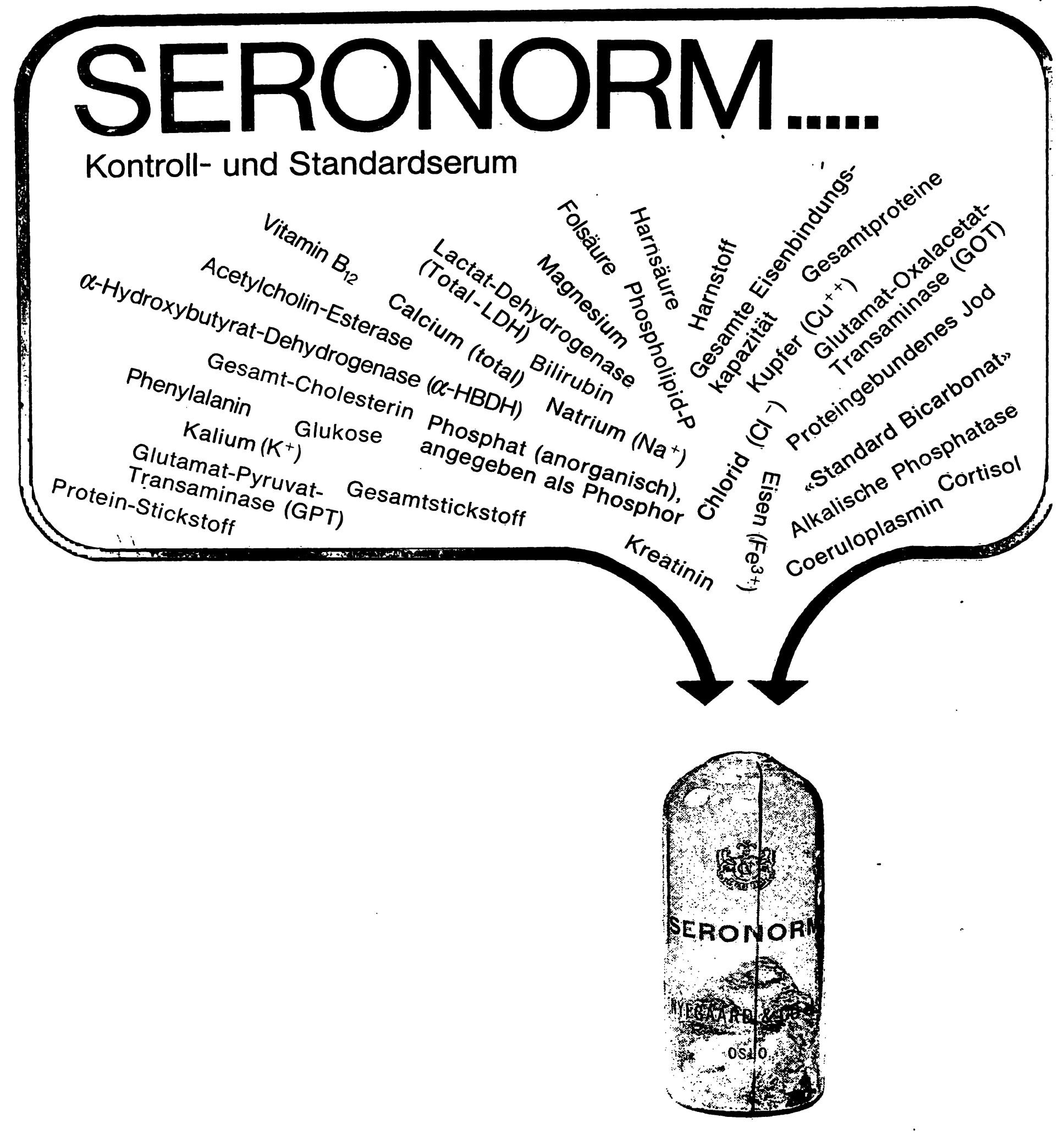

\section{SERONORM}

enthält 32 analysierte Serumkomponenten, deren empfohlene Werte in 5 anerkannten Laboratorien nach verschiedenen modernen Methoden festgelegt sind.

\section{SERONORM}

ist in der verschlossenen VakuumAmpulle 4 Jahre haltbar und in Packungen zu $5 \times 10 \mathrm{ml}$ erhältlich.

\section{SERONORM}

gehört auch in Ihr Laboratorium, denn es ermöglicht Ihnen die laufende Uberwachung Ihrer. Analysenwerte.

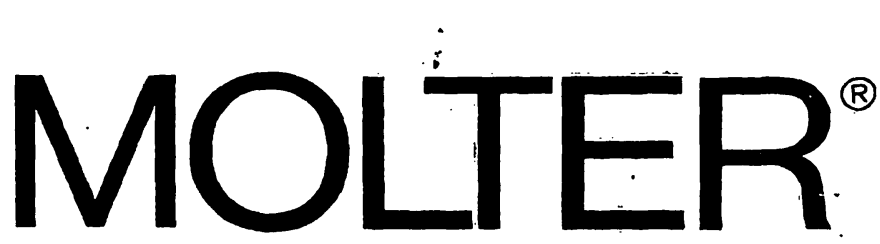

Dr. Molter $\mathrm{GmbH}$, Serum-lnstitut, 69 Heidelberg 1 Postfach 1210, Telefon 06223/5337 
Die Angabe von Grenzwerten in einem physiologisch interessanten Bereich kann dem Diagnostiker zwar erste Anhaltspunkte geben, ist aber doch als unbefriedigend anzusehen. Es wurde daher der Versuch unternommen, über das in der Praxis gut bewährte Verfahren des Zumischens organischer Flüssigkeiten zu der Probe eine Steigerung der Strahlungsintensität zu erreichen, die ausreichend für effektive Lithium-Angaben ist.

Erste Anhaltspunkte für die Größe der Beeinflussung können aus den beiden Spektren der Abbildung 3 entnommen werden.

Bei Spektrum 1 wurde die Verdünnung der Haupteichlösung 1:4 mit Wasser vorgenommen, bei Spektrum 2 eine solche mit Methanol. Die Emissionssteigerung um etwa einen Faktor 6 bei Verwendung einer methanolischen Lösung ist, wie aus den weiteren Spektren von Abbildung 4 erkennbar wird, ausreichend, um die Anwesenheit von Lithium in Seren feststellen

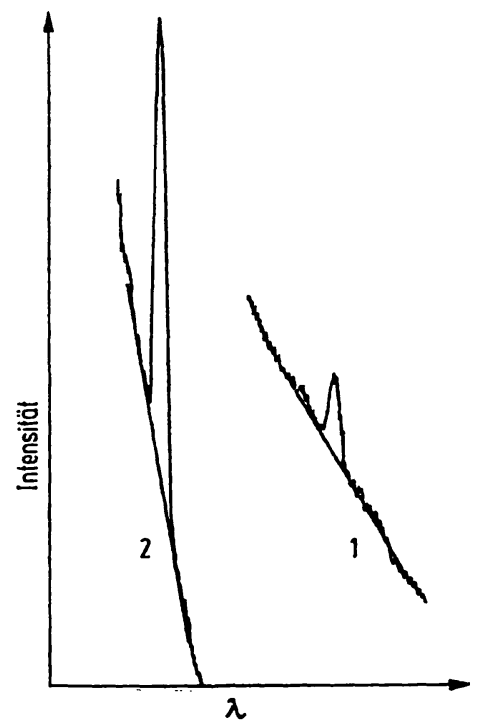

Abb. 3

Emissionsspektren der Haupteichlösung im Bereich der LithiumLinie $\lambda=6708 \AA$ (effektive Bandbreite des Monochromators etwa $1 \mathrm{~nm}$ ). Spektrum 1 Nachverdünnung 1:4 mit Wasser Spektrum 2 Nachverdūnnung 1:4 mit Methanol

zu können. Zur Herstellung der Meßlösungen wurde folgendes Verfahren angewendet:

a) $1 \mathrm{~m} /$ Serum wird mit $1 \mathrm{~m} /$ dest. Wasser und $1 \mathrm{~m} /$ Trichloressigsäure ( 40 proz.) versetzt, nach etwa $10 \mathrm{Min}$. werden weitere $7 \mathrm{~m} /$ dest. Wasser zugegeben und zentrifugiert. Anschließend wird, nachdem die dekantierte Lösung vorsichtig fast zur Trockne eingeengt ist, der Rückstand mit $5 \mathrm{~m} /$ Methanol aufgenommen.

b) Analog zu a) werden $1 \mathrm{~m} /$ Haupteichlösung bzw. $1 \mathrm{~m} /$ Blindlösung vorsichtig eingeengt, der Rückstand mit $5 \mathrm{~m} /$ Methanol aufgenommen.

Das eingesetzte Serum (Abb. 4) ist identisch mit dem Serum des Spektrums 2 von Abbildung 2. Zur gleichzeitigen Prüfung der Reproduzierbarkeit der Probenvorbereitung a) wurden drei Ansätze vorgenommen, wobei bewußt der Grad des Eindampfens unterschiedlich gehalten war.

Die Auswertung der Spektren liefert unter Anwendung der Proportion
(1) $C_{x}=C_{s} \cdot \frac{M_{x}}{M_{s}}$ mit $C_{x}:$ Lithium-Konzentration des Serums

$C_{s}$ : Lithium-Konzentration der Haupteichlösung

$M_{\mathbf{x}}$ : Meßwert des Serums minus linear interpolierter Wert des Untergrundes $(\lambda=6708 \AA)$

$M_{8}$ : Meßwert der Haupteichlösung minus linear interpolierter Wert des Untergrundes $(\lambda=6708 \AA)$

für das untersuchte Serum folgende Lithium-Werte:

Serum 2 a : $2,0 \mu \mathrm{g} / 100 \mathrm{~m} l$

Serum $2 \mathrm{~b}: 1,9 \mu \mathrm{g} / 100 \mathrm{~m} l$

Serum $2 \mathrm{c}: 1,9 \mu \mathrm{g} / 100 \mathrm{ml}$

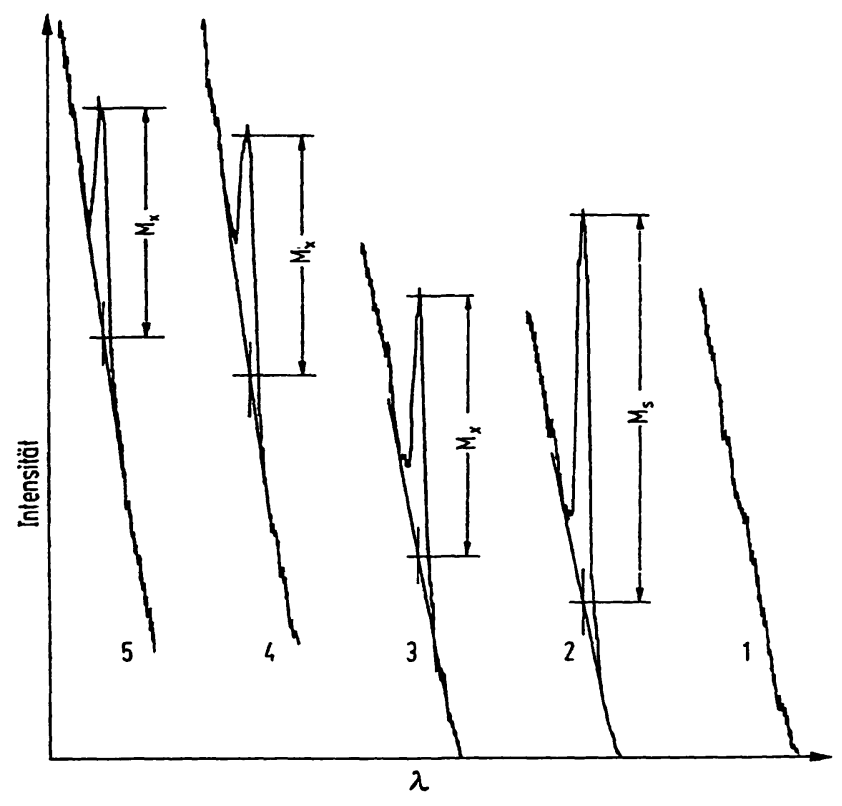

Abb. 4

Emissionsspektren eines nach Enteiweißung mit Methanol $1: 4$ verdünnten Serums (Spektrum 3-5) bzw. der analog verdünnten Hauptdünnten Serums (Spektrum 3- Blingw. der analog verdunnten Haupt der Lithium-Linie $\lambda=6708 \AA$ (effektive Bandbreite etwa $1 \mathrm{~nm}$ )

Es sei darauf hingewiesen, da $\beta$ beim Auftreten eines Blindwertes im Spektrum 1 dieser bei dem Meßwert $M_{\mathbf{s}}$ zu berücksichtigen ist. Die Verwendung von Gleichung (1) setzt eine weitgehende Anpassung der Eich- und Probelösung voraus. Im wesentlichen dürfte diese Bedingung durch die Elektrolytzusammensetzung der Haupteichlösung bzw. durch die Enteiweißung des Serums herbeigeführt sein. Die vorgenommene Verdünnung von Serum und Haupteichlösung schließt jedoch geringe Abweichungen zwischen Eich- und Probelösung besonders bezüglich physikalischer Größen wie Oberfächenspannung und Viskosität nicht absolut aus.

Eine Gegenüberstellung der Ergebnisse von Seren, die sowohl nach dem hier beschriebenen Verfahren als auch nach Veraschung analysiert wurden, ergab jedoch keine Anhaltspunkte für das Auftreten zusätzlicher Störungen.

Mit zwei weiteren Meßreihen sollte die Bestätigung erbracht werden, daß die lineare graphische Interpolation des Untergrundes aus den registrierten Spektren durch eine lineare rechnerische unter Zugrundelegung von zwei Einzelmeßwerten ersetzt werden kann. 
Tab. 1

Wertetabelle zur Lithium-Bestimmung eines Serums mit Untergrundinterpolation aus je 2 Stützwerten (Meßwerte in relativen Einheiten)

\begin{tabular}{|c|c|c|c|c|c|c|c|c|}
\hline & 1 & 2 & 3 & 4 & 5 & $\begin{array}{l}\text { Untergrundwert bei } \\
\lambda=6708 \AA \text { ermittelt } \\
\text { aus den Werten } \\
\text { Spalte } 1 \text { und } 5\end{array}$ & $\begin{array}{l}\text { Untergrundwert bei } \\
\lambda=6708 \AA \text { ermittelt' } \\
\text { aus den Werten } \\
\text { Spalte } 2 \text { und } 4\end{array}$ & $\begin{array}{c}\text { effektiver Lithium-Meß- } \\
\text { wert }=M \text { Meßert bei } \\
\lambda=6708 \text { A minus } \\
\text { Untergrundwert }\end{array}$ \\
\hline $\begin{array}{l}\lambda[\AA] \\
\text { Haupteichlösung } \\
\text { Serum 3a } \\
\text { Serum 3b }\end{array}$ & $\begin{array}{r}6640 \\
13,8 \\
9.8 \\
6,5\end{array}$ & $\begin{array}{r}6690 \\
11,0 \\
7,8 \\
5,5\end{array}$ & $\begin{array}{r}6708 \\
14,2 \\
7,4 \\
5,4\end{array}$ & $\begin{array}{c}6730 \\
8,0 \\
6,0 \\
4,3\end{array}$ & $\begin{array}{r}6780 \\
5,6 \\
4,0 \\
3,2\end{array}$ & $\begin{array}{l}9,7 \\
6,9 \\
4,9\end{array}$ & $\begin{array}{l}9,5 \\
6,9 \\
4,9\end{array}$ & $\begin{array}{c}4,5 / 4,7 \\
0,5 \\
0,5\end{array}$ \\
\hline
\end{tabular}

Bei der wellenlängenmäßigen Festlegung der beiden Stützwerte ist aufgrund der aus Spektrum 4, Abbildung 1, ersichtlichen geringen konvexen Krümmung darauf zu achten, daß diese in unmittelbarer Nähe jedoch außerhalb der jeweiligen Bandbreite des Monochromators - $\operatorname{der}$ Analysenlinie $\lambda(\mathrm{Li})=6708 \AA$ liegen. Die in Tabelle 1 zusammengefaßten Werte verdeutlichen allerdings, daß die Einstellung eine geringe Varianz zuläßt.

Gemessen wurden 2 nach Verfahren a) vorbereitete Lösungen des Serums von Spektrum 3, Abbildung 2, sowie die nach Verfahren b) vorbereitete Lösung der Haupteichlösung mit einer effektiven Bandbreite von etwa $1 \mathrm{~nm}$. Gleichung (1) liefert mit den Werten von Tabelle 1 einen Lithium-Gehalt des Serums von $0,5 \mu \mathrm{g} / 100 \mathrm{~m} /$. Der zweite Versuch unter Verwendung des Serums von Spektrum 2, Abbildung 2, ergibt nach Einzelmessung und rechnerischer Interpolation des Untergrundes folgende Lithium-Werte:

Serum $2 \mathrm{a}: 1,5 \mu \mathrm{g} / 100 \mathrm{~m} l$

Serum $2 \mathrm{~b}: 1,4 \mu \mathrm{g} / 100 \mathrm{~m} l$

Serum 2 c: $1,8 \mu \mathrm{g} / 100 \mathrm{~m} l$

Dem Mittelwert von 1,9 $\mu$ g Lithium $/ 100 \mathrm{~m} l$ Serum bei graphischer Interpolation steht somit ein solcher von $1,6 \mu \mathrm{g} / 100 \mathrm{~m} /$ Serum bei rechnerischer Interpolation gegenüber.

Im Hinblick auf die Größenordnung der Lithium-Konzentration kann dieses Ergebnis als durchaus befriedigend angesehen werden.

\section{Erfahrungen bei Routineanalysen - Genauigkeit der Methode}

Der aus dem vorstehenden Abschnitt resultierende Analysengang, bestehend aus dem Herstellen der Meßlösungen nach a) und b), der Messung bei $\lambda=6708 \AA$ bzw. der Ermittlung des Untergrundes aus zwẹi Stützwerten sowie der Berechnung der Lithium-Konzentration nach Gleichung (1), erwies sich für Routineanalysen als nicht $z u$ aufwendig. Für 17 nach diesem Verfahren analysierte Seren ergaben sich nachstehende Lithium-Konzentrationen:

$\begin{array}{llllllllllll}\text { Serum } & 1 & 2 & 3 & 4 & 5 & 6 & 7 & 8 & 9 & 10 & 11\end{array}$ Lithium-Gehalt 1,2 0,7 1,0<0.5<0,5<0,5<0,5<0,50,50,7 1,8 $[\mu \mathrm{g} / 100 \mathrm{ml}]$

$\begin{array}{lrrrrrr}\text { Serum } & 12 & 13 & 14 & 15 & 16 & 17 \\ \text { Lithium-Gehalt } & 1,7 & 0,6 & 0,6 & 1,5 & 1,2 & 1,2\end{array}$ $[\mu \mathrm{g} / 100 \mathrm{ml}]$

In Übereinstimmung mit den Untersuchungen von LANG und Herrmann lassen auch diese Analysen einen physiologischen Lithium-Mittelwert für nicht pathologische Seren von $<3 \mu \mathrm{g} / 100 \mathrm{~m} l$ Serum erwarten.

Die Genauigkeit des Verfahrens, ausgedrückt durch den Variationskoeffizienten, errechnet sich aus den Analysen eines Mischserums mit $0,7 \mu \mathrm{g} \mathrm{Li} / 100 \mathrm{~m} l$ Serum zu $\mathrm{V} \sim \pm 20 \%$. Für Lithium-Werte, die weiter oberhalb der Nachweisgrenze von $0,5 \mu \mathrm{g} \mathrm{Li} / 100 \mathrm{~m} l$ Serum liegen, geht der halb-quantitative Charakter der Analyse in einen quantitativen über.

\section{Literatur}

1. Lang, W. und R. Herrmann, Zschr. exper. Med. 139, 200 (1965). - 2. DoERR, D. und D. StaMm, diese Z. 6, 178 (1968). 3. Hinzberg, K. und K. Lang, Medizinische Chemie für den klinischen und theoretischen Gebrauch, 3. Auf. Urban \& Schwar- zenberg, München-Berlin-Wien (1957). - 4. Merck, E., Medizinisch-Chemische Untersuchungsmethoden, 11. Aufl., Verlag Chemie GmbH, Weinheim/Bergstr. (1970).

R. Klaus

E. Merck AG.

61 Darmstadt

Frankfurter Str. 250 